\title{
BULGARIAN EXPERIENCE IN THE DEVELOPMENT OF MILITARY CONCEPTS
}

\author{
Neno Hristov \\ Colonel Associate professor Ph.D., D. Sc., Military Academy, Sofia, Bulgaria, neno.hristov@gmail.com
}

\begin{abstract}
According to national and Union terminology, a concept is understood to mean "a concept or formulation of an idea expressing how something can be done or accomplished to bring about an acceptable way of action“.

On this basis, concepts can be considered as a set of three mutually agreed or balanced bindings - objectives, ways and means. Military concepts usually describe how to use certain military capabilities to achieve a goal or the way to solve a particular problem, and this can lead to changes in doctrines, organization, procedures, training, armament requirements, combat equipment, equipment, equipment and others.

Goals determine the desired end state. They can vary in a wide range - from national targets to a single task. In the military field, goals are set in strategies, planning national or operational documents, and orders to individual formations.

The mode of action is a description of the ways to achieve the ultimate goals or the ultimate state by using the appropriate forms, methods, methods and tactics. These are the actions with the available or planned means to achieve the goals. The essence of the concept is the description of these ways, including sequence or

In the military field the means are an expression of the military power of the armed forces at a certain point in their development. Depending on the usability of the armed forces and the level of command as a means, the Armed Forces as a whole, the Joint Operational Forces, the type of armed forces and tactical formations can be considered to achieve the lowest level of ability - separate elements (the Armament System).

The development of ideas in approaches and applicable modes of action requires the fitting of appropriate means (military capabilities) that are likely to achieve the goals set. Goals set the meaning of the follow-up, and the resources determine what resources to be set. Defining how to act is the essence of the concept. Their role is to link goals to resources. From this follows the conclusion that military concepts basically describe how an idea can be realized.
\end{abstract}

Keywords: concept, military concepts, military capabilities, defense capabilities, capability-based planning, doctrines, organization, procedures, developing concepts, goals determine, desired end state 


\section{INTRODUCTION}

The process of developing concepts is an integral part of the development of capabilities. It provides guidance for defining the necessary defense capabilities and provides solutions to overcome their deficiencies.

The aim of the article is to present the basics of the conceptual method in the context of capability-based planning by defining the concept of concept, the types of concepts, the interrelations of concepts with other regulatory documents in the field of defense and the armed forces, and describing the process of developing concepts in the armed forces of the Republic of Bulgaria.

The article provides a systematic approach to the development and implementation of military concepts (national, union, etc.) and provides practical guidance and methodology for their assessment.

According to national and Union terminology, a concept is understood to mean "a concept or formulation of an idea expressing how something can be done or accomplished to bring about an acceptable way of action."

On this basis, concepts can be considered as a set of three mutually agreed or balanced bindings - objectives, ways and means. Military concepts usually describe how to use certain military capabilities to achieve a goal or the way to solve a particular problem, and this can lead to changes in doctrines, organization, procedures, training, armament requirements, combat equipment, equipment, equipment and others.

Goals determine the desired end state. They can vary in a wide range - from national targets to a single task. In the military field, goals are set in strategies, planning national or operational documents, and orders to individual formations.

The mode of action is a description of the ways to achieve the ultimate goals or the ultimate state by using the appropriate forms, methods, methods and tactics. These are the actions with the available or planned means to achieve the goals. The essence of the concept is the description of these ways, including sequence or............

In the military field the means are an expression of the military power of the armed forces at a certain point in their development. Depending on the usability of the armed forces and the level of command as a means, the Armed Forces as a whole, the Joint Operational Forces, the type of armed forces and tactical formations can be considered to achieve the lowest level of ability - separate elements (the Armament System).

The development of ideas in approaches and applicable modes of action requires the fitting of appropriate means (military capabilities) that are likely to achieve the goals set. Goals set the meaning of the follow-up, and the resources determine what resources to be set. Defining how to act is the essence of the concept. Their role is to link goals to resources. From this follows the conclusion that military concepts basically describe how an idea can be realized.

From a practical point of view, the concept should combine the answers to the following main questions:

What needs to be achieved?

Why is it necessary to achieve it?

How can it be achieved?

What abilities are needed?

Depending on the timeframes for which the concepts refer, they can be classified into three main groups historical, current and future.

Historical - concepts applied in the past, regardless of whether a distant or close stage of the past is considered. The means, forms, and perceptions of warfare are continually being developed. There are various publications and scientific papers that examine their interrelations with public systems, religion, technology, weapons, national power, and so on. All of them deserve to be studied and studied, in view of the fact that new ideas often originate and develop on the basis of the old ones.

It is known from the story that sometimes new concepts or views on the use of the armed forces have been developed in advance, and in other cases they have emerged as a result of the circumstances. This shows that implementing an innovative approach to seeking new ways of acting can be a purposeful, manageable process.

In this process, the role of historical concepts is to provide knowledge about the changes in warfare, the trends 
of the different ages, the significance of discoveries and the introduction of technology. Historically, conceptual evaluation allows for a realistic approach, eliminates insubstantial concepts, and prevents the use of unjustified resources (human, material, temporal) or tragic consequences.

Contemporary - concepts that relate to currently available abilities and are in line with technological development and accepted modes of action. These concepts through the defense planning process of previous stages are embedded in all elements ${ }^{1}$ of the available capabilities and can be directly found in current doctrinal documents, tactics, techniques, procedures and plans.

The development of capabilities implies modifying and refining capabilities, and in particular doctrines. This is a process of smooth changes, where the main driving factor is the operations and the training of the armed forces. In this case, "lessons learned from practice" are "feedback" to make changes to the doctrinal basis. It is not necessary to develop a new concept for the introduction of this kind of smooth changes without changing the nature of the capabilities.

Future - concepts that present the views of using the armed forces in the future security environment. Initially, future military concepts are a hypothesis or statement that is subject to development and analysis. In practice, it is necessary to establish the applicability of the developed ideas through the process of experimenting and undergoing a wide-ranging discussion. As a result of this process, the concepts developed are either applied or rejected as inappropriate or insufficiently effective. Future military concepts are at the heart of the capability development process.

The concept of the operation is a graphic or written formulation of the commander's intentions to conduct an operation or a series of operations. The concepts of operations are set out in the Operations Plans of Operations or Campaigns. They are designed to give an overview of the operation as a whole. The main purpose of the concept of the operation is to clarify the way of action to achieve the goal. It is known as CONOP.

For the capability development process, the term operational concept is introduced. The aim is to distinguish these concepts from the concepts of operations. Operational concepts describe operations as a set of different types of combat and other military action. The concept of "operational concept" is introduced with the aim of generalizing in the broadest sense all military actions. Some operational concepts in their implementation may cover more than one level of command and control.

Concepts and doctrines have some similarities and, at the same time, significant differences arising from their nature and purpose. Nevertheless, the two types of documents remain closely related and interdependent.

Concepts and doctrines are the products of knowledge and their purpose is to present the ways in which the armed forces operate (they answer the question "How?").

An essential feature of doctrines that distinguishes them from concepts is that they refer to available capabilities and are the basis of staff training and training for the armed forces.

Concepts, though subject to verification and experimentation, are in essence ideas that relate to the future. As such, they provide an opportunity to meet challenges that may not be the subject of doctrines. Unlike doctrines in concept development, the impact of specific policies, contracts, or legal documents must be minimized and, if possible, even excluded. This provides a high degree of freedom to developers and the leading role of the expert team to look for new, objective ways of action.

Concepts and doctrines have a leading role in defining the organization's tasks. The difference lies in the fact that doctrines are applied to the realization of military power under certain available capabilities frameworks, and the concepts - when looking for alternatives to the necessary capabilities in the defense planning process.

Concepts are developed on the basis of existing or suspected future threats, regardless of the extent of their impact. Therefore, they need to be realistically developed, whether they are for the present or the future.

Concepts have the clear goal of improving the effectiveness of the armed forces, including through changes in doctrines, but not all doctrinal changes require the development of a concept. The development of doctrines is a continuous, coherent, evolutionary process that is well structured.

\footnotetext{
${ }^{1}$ Military capability is a collection of the following elements: doctrines; organizational structure; Preparation; material resources; personnel; Command and control; Infrastructure and interoperability.
} 
Military concepts can be developed to change targets that are put to the armed forces after acquiring new abilities, detecting a deficiency of abilities, or looking for ways of acting for more effective capabilities.

Concepts are developed in response to such changes in the security environment for which no alternatives exist at the time of their emergence, and there is a perceived need for a timely and adequate response. For example, the emergence of a new breakthrough technology in the field of wireless transmission over long distances would require both a comprehensive review of concepts in the economic and social spheres, and the development of a concept for its use in the security and defense system. Such technology would radically change the architecture and methods of using and maintaining combat platforms. In this sense, the concept leads to changes in doctrines, organization, techniques, tactics and procedures, means and methods of preparation, etc., and in certain cases even qualitative changes in the requirements to the abilities and in the system of their construction and maintenance.

The concepts contribute to adapting the armed forces to the security environment by introducing changes in capabilities. Their development is in line with the horizon and the prospects set out in the national strategies. Their contribution to the next strategic documents is to provide modern means of conducting operations. Concepts are needed to determine military capabilities to address security challenges or resolve problems related to skills shortages. This task is solved in the first phase of the defense planning process - the "Planning" phase.

The process binds changes in the security environment with the political decisions made and defining the necessary capabilities to achieve the defense objectives. It includes the following basic steps:

Implementation of policy guidelines;

Defining and refining missions and tasks;

Determining the necessary capabilities;

Analysis and assessment of available capabilities;

Determining the discrepancy between existing and necessary capabilities, analyzing the skill deficit;

Developing and selecting options to overcome skill shortages;

Developing an Armed Forces Development Plan;

Elaboration of the MoD investment plan.

Political guidelines on defense planning are given by the Minister of Defense and include an assessment of the security environment, the level of ambition to use the armed forces, the role of the armed forces, defense policy priorities, the names of the general planning scenarios and the foreseeable financial framework.

On this basis, the missions and tasks to be decided by the armed forces in 15-20 years will be defined and refined.

Basic concepts play a key role in determining the necessary capabilities. They enable realistically identifying achievable operational capabilities based on the policy framework set. This is achieved by developing several scenarios to achieve the goals. In their development, it is imperative to take into account the commitments made by the country to allies and partners, related to the development of capabilities with a time horizon of 10-12 years.

Comparing what is needed with existing capabilities indicates whether the necessary are available to the armed forces. This compares the capabilities of the current structure of the Armed Forces with that of the structure that will be needed in the future to identify the mismatch between them.

Once the skill deficit is identified, options are developed to overcome it. The options for overcoming the deficit are developed in concepts indicating how to solve the problems. When overcoming the skill shortage, these concepts are most often applied, which lead to the modernization or acquisition of new equipment and new material assets. These concepts are short-term, but require significant financial resources. Particular attention is paid to such concepts that offer changes in doctrine, training, organization, material and stock, education, and so on. And can solve the problem.

In the process of developing concepts, uncontrolled development and unjustified restrictions hide threats, given 
the creative nature of generating and developing ideas. In order to establish purposefulness and manageability in the development process of the conceptual basis, the classification of concepts and the resulting basic characteristics are of crucial importance.

Each NATO member state develops its national system for the classification and organization of the concept development process. Based on the lead experience of leading countries in concept development, the following approaches are highlighted:

In time horizons - historical, current and future;

Hierarchical - institutional, operational, functional (main areas and sub-areas) and supportive;

According to the purpose of the concepts - fundamental, supportive and applied;

By degree of development of the idea - analytical, theoretically reasoned and applicable.

The national classification of the conceptual base is constructed according to the following requirements:

To meet the tasks and capabilities of the national defense system;

To conform to the knowledge development system;

Be in line with NATO and EU allied systems;

To complement NATO and EU allied systems.

The hierarchical model is best suited to military concepts. Through it, horizontal and vertical relationships and consistency are realized and maintained. Vertical interconnections take place, with a higher level concept evolving into a concept (or group of concepts) from a lower one.

Since each concept encompasses a variety of situations in which the chosen mode of action is the result of the application of common principles, lower-level concepts develop the common ideas set at a higher level, provide guidance in terms of specific conditions and support the realization of them.

Concepts based on common approaches and using generalized or more abstract concepts occupy higher levels in the hierarchy. Higher level concepts set the common sense and have a leading role in developing their corresponding lower-level concepts.

Lower level concepts address specific issues and describe in greater detail specific topics that are part of a corresponding higher-level concept.

Concepts from the lower levels must match the contents of the higher levels and develop them further.

The National Conceptual Base has a hierarchical structure (Figure 1) with the following levels:

Institutional concepts;

Operational concepts;

Functional concepts;

Supporting concepts.

Institutional concepts occupy the highest place in the hierarchy and concern the national security system as a whole. They develop ideas that contribute to the functioning of the national security system and concern sectoral defense policy.

Institutional concepts have the highest priority. They derive directly from the defense policy and the national documents - the National Security Strategy of the Republic of Bulgaria and the National Defense Strategy. Institutional concepts are the basis for building future armed forces and providing guidance for developing operational concepts.

Operational concepts provide the means of conducting operations by future armed forces. An essential feature of these concepts is their focus on military operations. In the case of operations involving other structures, these concepts only deal with the military part of the joint actions. The main objectives of the operational concepts are to achieve the effects determining the respective ending states and requirements to the required capabilities. 
In hierarchical terms, operational concepts are developed at strategic, operational and tactical levels.

Operational concepts can provide guidance for developing functional and corresponding supporting concepts. In their essence, they are a generalized idea of using military force under certain parameters and in combining military science with military art.

The following key elements can be derived from the definition:

"Generalized Idea" - Military Operational Concepts should reflect generalized principles or consider typical environments rather than solutions to specific problems or individual situations. This requires the development of common (universal) approaches and the search for ways to apply them to the practice of the armed forces;

"Defined parameters" (reporting of the environment) - each developed concept should take into account the environment to which it is concerned and influence factors influenced. Typically, the environment imposes certain constraints and requires the establishment of certain assumptions. Restrictions and assumptions are intended to reduce the uncertainty of the environment. Assumptions must be rational and logically related to the environment. The extent and impact of constraints and assumptions may vary to varying degrees with individual concepts - individually, in groups, or have an accumulative effect. Fewer conventions should be contained in higher-level concepts.

"Combining military science with military art" - the concepts cover all kinds of military action and activities. When developing a particular type of operation, they must engage in military functional areas, phases of operations and forces formed by the armed forces, to be bound to the elements of abilities. This gives universality and reasonability and is in line with military art and science. In the most general sense, they describe what the armed forces should achieve under certain conditions, how to achieve it, or, in other words, how to apply military force most effectively.

Approaches to determining the parameters of operating concepts are:

Mission type - Operational concepts can be categorized according to the type of mission to which they refer (depending on objectives);

Command and management level - insofar as an operational concept refers to a certain level of command and management, they are considered as concepts at a strategic, operational or tactical level. It is not excluded that at an early stage in formulating the concept it should be referred to a specific level, in which case it can be transformed into two concepts that relate to two of the levels or to some of the functional concepts ;

Organizational structure of the armed forces - has an impact on the way the operation is carried out. Typically, the organizational structure is the result of factors such as the coalition format of the mission, participation of species and clan troops, physical and geographic conditions, etc.;

Operating environment - impacts on the conceptual document. It is mainly determined by the political environment, the type of operation, the ratio of forces and their technological level, the geographical environment and the hydro meteorological conditions of the area in which the operation takes place.

Functional concepts are military concepts describing a specialized area of military ability to achieve the desired effects. In the process of developing these concepts, the requirements for the necessary capabilities grouped into functional areas are leading. Their goal is to identify practical ways to solve problems related to the capabilities they provide for further development in lower level concepts.

Supportive concepts describe the specific abilities necessary for the functioning of an area. They have a very practical focus and describe how to act for a particular task or procedure, relying on technical solutions, innovations in combat training or educational program, organization, infrastructure, etc.

Taking account of concept levels, supportive concepts are more specific and developed in more detail. The preferred style of texts is to give guidance that will later serve to formulate military capability requirements.

When developing a concept, especially in the initial stages, inconsistencies in hierarchical dependencies and exceptional deviation from the classification are allowed. This is because of the high degree of uncertainty in the presentation of the initial ideas. Inconsistencies are overcome in the final stages or by developing a supportive concept that fills the gap resulting from the mismatch of priorities. 


\section{REFERENCES LIST}

Ansoff, H.I., (1999) Strategic Management. London: Macmillan, 1990. Axelrod, Alan. Patton on Leadership: Strategic Lessons for Corporate Warfare. Paramus: Prentice Hall.

Digman, Lester A., (1993) Strategic Management: Concepts, Decisions, Cases. Homewood: DPI Irwin, 1990. Goodstein, Leonard A., Timothy M. Nolan and J. William Pfeiffer, Applied Strategic Planning: A Comprehensive Guide. New York: MaGraw-Hill.

Mintzberg, H., (1994) The Rise and Fall of Strategic Planning: Re-conceiving Roles for Planning, Plans, and Planners. New York: The Free Press.

Terziev, V., N.Nichev, (2016) Ikonomicheski harakteristiki na ofestnite sdelki s otrbranitelni produkti, Scientific journal „Economics and Finance”, Problems of development modern science: Theory and practice Collection of scienfic articles, pp.101-106.

Terziev. V., Stoyanov E. N. \& Georgiev M.P. Modelyt balasdirana karta za ocenka kato instrument za usyrvyrshestvane na upravlenieto v rabotata na nacionalna Sistema za otrbrana i sigurnost. Research: tendencies and prospects: Collection of scientific articles, pp.7-11.

Terziev. V., N.Nichev, (2017) Osnovni harakteristiki na kompensaciite $v$ tyrgoviqta s otbrana. Proceedings of SOCIOINT 2017- 4th International Conference on Education, Social Sciences and Humanities, pp.661666.

Dimitrova, S., V. Terziev, Finansovo obezpechavane - osnovni za strategichesko resheniq a upravlenie na resursite za sigurnost $\mathrm{i}$ odbrana, The 21th International Conference Knowledge-Based Organization, „Nicolae Balescu” Land Forces Academy, Publishing House Sibiu, The Knowledge-Based Organization, Vol. XXI, N 2. 